\title{
BLICKDIAGNOSE
}

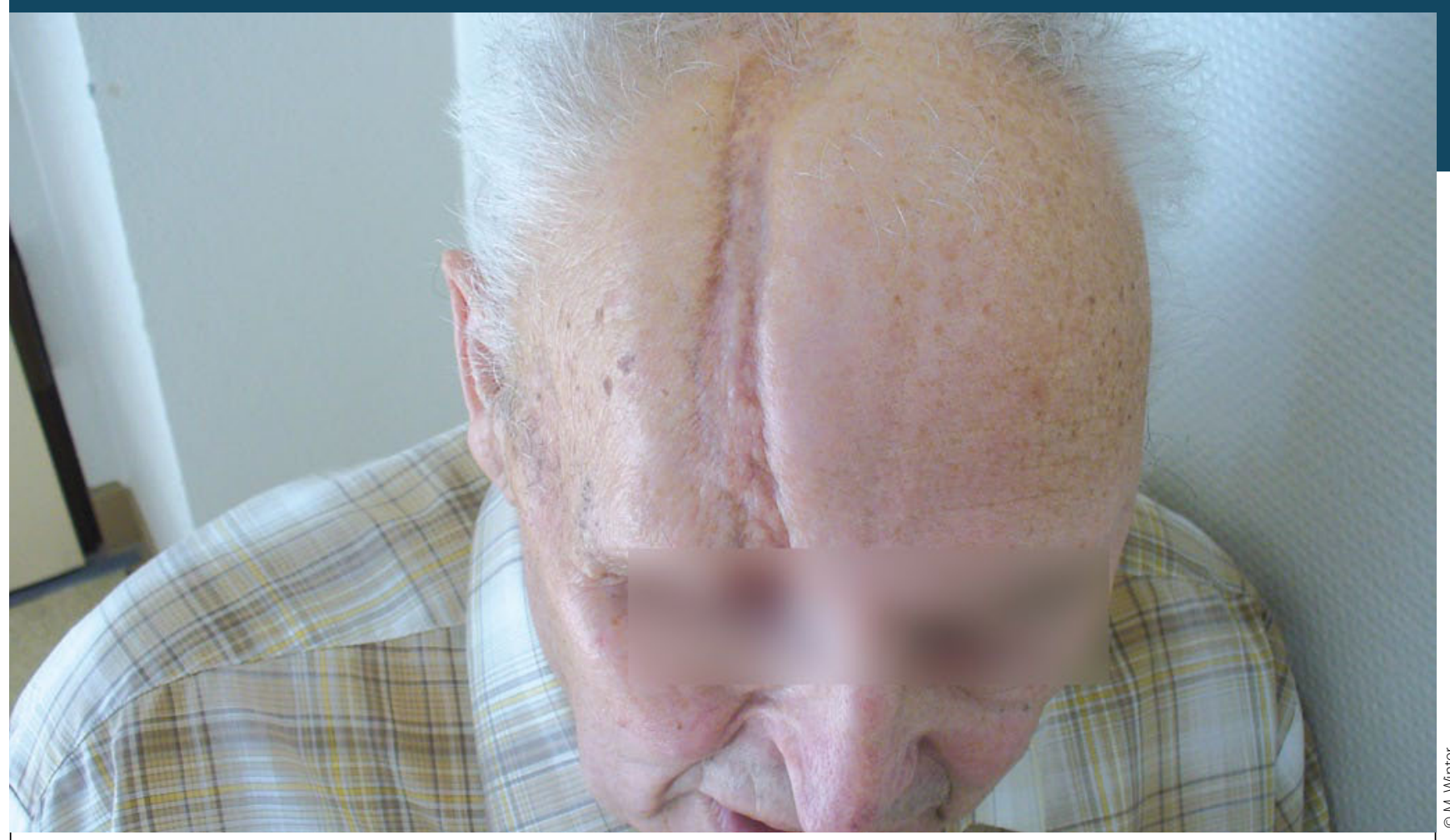

Auffällige Narbe bei einem 80-Jährigen

\section{(K)ein Säbelhieb}

Der 80-jährige Patient wurde nach einer Synkope stationär aufgenommen. Er hatte die abgebildete Narbe auf der rechten Stirn und paranasal.

Die Frage nach einem früheren Trauma wurde vom Patienten verneint. Es handele sich um eine Sklerodermie. Diese habe sich im Alter von etwa 40 Jahren so entwickelt, auch der Knochen sei betroffen gewesen. Danach habe es keine weiteren Veränderungen mehr gegeben und auch keinen Befall anderer Organe.

Es handelt sich um eine lokalisierte Sklerodermie, eine sklerotische Verhärtung des Bindegewebes der Haut, die auf schmale Bezirke beschränkt ist. Auch die Faszie kann befallen werden. Es kann zur Atrophie von Knochen und subkutanem Bindegewebe kommen.

Diese Atrophieherde können an Narben nach einem Säbelhieb (frz. Coup de Sabre) erinnern. Innere Organe werden bei dieser Form nicht befallen.

Keywords: scleroderma en coup de sabre

- Dr. Matthias Winter, Internist - Allgemeinarzt, KH Crailsheim, Gartenstraße 21, D-74564 Crailsheim

\section{www.springermedizin.de}

Weitere Blickdiagnosen finden Sie im Internet unter: http://www.springermedizin.de/blickdiagnose 